\title{
Deteriorating Environmental Resources and Primary School Educational Attainment in the Rural South Pare Highlands, Tanzania
}

\author{
Romanus Lucian Dimoso \\ Dept. of Economics, Mzumbe University \\ P.O. Box 5, Mzumbe, Morogoro, Tanzania \\ Tel: 255-787-084-266Ｅ-mail: rdimoso@yahoo.co.uk
}

Received: December 7, 2011 Accepted: January 12, 2012 Published: March 1, 2012

doi:10.5296/ije.v4i1.1147 URL: http://dx.doi.org/10.5296/ije.v4i1.1147

\begin{abstract}
We assess whether school attendance and progress of children in rural primary schools, with respect to their gender, is inversely affected by deteriorating environmental resources. We distinguished three types of areas, namely, severely-degraded, medium-degraded and non-degraded environmental conditions. Our findings, among others, show that there were other factors like school crowdedness, illness, bad weather, school absenteeism due to petty trading and/or informal casual labour, and poor quality of some primary schools that significantly affected the probability of school attainment for the schoolchildren apart from the environmental degradation situations. Environmental degradation, in all estimates except for the schoolgirls in severely-degraded environment, did not have a significant impact. The policy makers therefore, in their attempt to improve educational attainment and human capital formation at primary level should, as well, focus on these other relevant factors excluded from our model. Moreover, the non-government sector may also be enticed into investing in education through attractive fiscal incentives.
\end{abstract}

Keywords: Environmental Degradation, Primary School Attainment, Rural South Pare Highlands, Tanzania 


\section{Introduction}

This paper tests whether school attendance and progress of children in rural primary schools, with respect to their gender, is inversely affected by deteriorating environmental resources. Schoolchildren are involved in the work, supporting their households' livelihoods, including housework, farming, collecting scarce environmental products and/or grazing. This type of child labour frequently leads to foregone schooling, which may have critical consequences for educational achievements. Understanding more about this form of child labour in the face of various degrees of environmental degradation, and its link to educational attainments is important.

\section{Data}

We used cross-sectional primary data obtained in 2006/7 from the south Pare highlands. South Pare is the most dramatic example of environmental degradation in Tanzania. The area is entirely confined to the Same district, with a land size of 5152 square kilometres, in Kilimanjaro region. The area is categorized into three main zones as per its geographical features. The zones are the Upland Plateau Zone (relatively non-degraded), the Middle Plateau Zone (medium-degraded) and the Lowland Zone (severely-degraded).

\subsection{Descriptive statistics}

We had a sample of 301 schoolchildren in our survey, one from each household. The criteria used for selection were primarily their familial relationship to the household head, their undoubted physical ability to perform various activities without difficulties, including collection and/or grazing and other agricultural and household work, were enrolled at primary schools and were able to express themselves. With regard to familial relationship, we preferred children who were living together with their biological parents.

Of these 301 schoolchildren, 152 (50.5 percent) were boys and 149 (49.5 percent) were girls. In general, 92 percent of these children reported that they attended school in the past 12 months while 8 percent reported they did not. The 8 percent who did not attend had either permanently or temporarily dropped out of school. In any case, if they would attend school next academic year they would have to repeat a grade. For those who attended school in the past 12 months, it happened that some missed school occasionally apart from allowed holidays and school breaks. 2 percent of the schoolchildren reported having missed school quite often, 75.4 percent missed school regularly and 22.6 percent never missed school during the whole academic year. The rainy season was reported as the period that schoolchildren most often missed school. 57.8 percent of the school-goers acknowledged having missed school quite often during the rainy season. 15.6 percent did not attend school most often during the dry season while 26.5 percent found the interview question not applicable suggesting that they either never missed school or seasonality had no direct connection with their school non-attendance.

There were several reasons explaining why they sometimes failed to attend school at the specified time. 40.5 percent cited illness as the major cause. 22.9 percent of the schoolchildren sometimes did not show up at school due to bad weather while 7 percent 
failed to come to school on some days because of collecting environmental products. Other causes were working at farms ( 3 percent), working at home (1.7 percent) and lack of stationery (3.7 percent). 20.9 percent of the schoolchildren respondents sometimes didn't attend due to 'other reasons'. We suspected this category might contain those not regularly attending school because of practicing petty trading in the street as the respondents were reluctant to admit the fact. Poor quality of some primary schools could also contribute to the problem of seasonal non-attendance though it was not questioned in the research instrument.

We did not find a significant difference in school attendance between girls and boys. Hours spent in collecting scarce environmental products and/or grazing, farming and domestic work, which might affect school attendance, did not differ significantly between boys and girls though gender bias prevailed for some activities like grazing for boys and housework, especially cooking, for girls (see Table 1).

All children specified their schools and respective classes. Ishinde primary school enrolled 10 percent of the survey schoolchildren. Other primary schools (Note 1) enrolled between 0.3 percent to 9.6 percent of the survey schoolchildren. These primary schools were located at a distance from each other at different villages in different environmental degradation conditions. Pupils were enrolled at a nearby school from the homestead. Villages in this study each had at least one primary school. These facilities were public and children rarely attended primary schools outside their village. The majority of schoolchildren in the survey households were concentrated in classes 4 to 6 . There were 33.6 percent, 21.9 percent and 16.6 percent in classes 6, 5 and 4, respectively. These were mature pupils and their physical labour force was essential in supporting their parents in agricultural activities, housework, collecting scarce environmental products and/or grazing. However, Class 7 pupils, though mature, might not be largely available as they were preparing themselves for the final examinations of accomplishing a 7-year primary school education. Their daily school schedules might also be very tight.

Schooling might result in both direct and indirect costs. The direct costs of schooling were mainly costs of uniforms and costs of school equipment, mainly stationery. Other equipment like textbooks were usually provided by the government, pupils found them at school though still in short supply. In the study area, parents had no custom of buying textbooks for their children. Other direct costs like school fees and enrolment fees (introduced in 1995) were eliminated by the Tanzanian government in 2002 (Burke and Beegle, 2004). Because each village had at least one primary school, almost no children had transportation or lodging expenditures. Under the Primary Education Development Plan (PEDP) developed within the context of the Education Sector Development Programme (ESDP) covering the period 2002-2006, primary school fees and other parental contributions were abolished at primary level and capitation grants were raised with an ultimate target of US\$ 10 per pupil (Mbelle and Katabaro 2003). Despite some allowable financial contributions for attending such expenditures like graduation festivals, direct costs of schooling were rather low in Tanzania (Burke and Beegle, 2004) and were not considered in our research instrument. Instead, we considered the indirect cost or rather the opportunity costs of schooling as the more relevant "cost" of schooling in our case. In particular, we focused on the hours pupils spent in school 
compared to hours in other activities. Since, by law, these pupils were prohibited to have formal employment, e.g. in government and private offices while still schooling, we considered formal employment activity as non-applicable and completely absent from the survey questionnaires. This, however, did not exclude the possibility that a few school pupils might have spent some time in non-farm self-employment in petty trading and similar businesses. However, this aspect of non-farm self-employment was not considered in the research instrument. To cater for its possibility, Table 1 includes a non-explained time-spent variable.

We emphasized seven broad areas of time use for schoolchildren in our sample. These were water fetching, fuel wood collection, grazing, agricultural work, household chores, schoolwork and leisure. In this paper, water fetching, fuel wood collection and grazing are referred to as scarce environmental product collection and/or grazing works.

Table 1: Distribution of time per week by environmental condition

\begin{tabular}{|c|c|c|c|c|c|c|}
\hline & \multicolumn{2}{|c|}{ Non-degraded } & \multicolumn{2}{|c|}{ Medium-degraded } & \multicolumn{2}{|c|}{ Severely-degraded } \\
\hline & Mean & Std. Dev & Mean & Std. Dev & Mean & Std. Dev \\
\hline \multicolumn{7}{|l|}{ Schoolboy } \\
\hline Water fetching hours & 5.04 & 2.54 & 6.16 & 4.49 & 11.24 & 8.71 \\
\hline Fuel wood collection hours & 3.38 & 1.67 & 4.12 & 2.99 & 7.50 & 5.80 \\
\hline Grazing hours & 2.35 & 2.26 & 3.60 & 3.40 & 6.13 & 6.77 \\
\hline Agriculture working hours & 8.01 & 5.67 & 7.54 & 5.39 & 11.77 & 6.73 \\
\hline Household chores hours ${ }^{\mathrm{a}}$ & 4.19 & 2.45 & 3.94 & 2.44 & 7.09 & 4.38 \\
\hline Leisure hours ${ }^{\mathrm{b}}$ & 80.09 & 8.04 & 78.35 & 24.80 & 55.66 & 29.16 \\
\hline School hours ${ }^{c}$ & 60.60 & 3.31 & 60.34 & 12.35 & 61.33 & 4.62 \\
\hline Unaccounted-for hours $^{\mathrm{d}}$ & 4.34 & & 3.93 & & 7.28 & \\
\hline Total & $\overline{168}$ & & $\overline{168}$ & & $\overline{168}$ & \\
\hline \multicolumn{7}{|l|}{ Schoolgirl } \\
\hline Water fetching hours & 4.93 & 2.18 & 6.02 & 3.78 & 8.74 & 6.79 \\
\hline Fuel wood collection hours & 3.30 & 1.43 & 4.02 & 2.51 & 5.84 & 4.51 \\
\hline Grazing hours & 1.90 & 2.02 & 2.61 & 2.83 & 3.90 & 4.80 \\
\hline Agriculture working hours & 9.23 & 5.18 & 7.51 & 5.92 & 9.35 & 7.13 \\
\hline Household chores hours ${ }^{\mathrm{a}}$ & 5.19 & 2.53 & 5.58 & 4.03 & 7.08 & 3.85 \\
\hline Leisure hours ${ }^{c}$ & 78.27 & 10.58 & 74.94 & 21.42 & 66.11 & 26.65 \\
\hline School hours ${ }^{\mathrm{d}}$ & 59.88 & 5.56 & 61.94 & 9.27 & 60.04 & 10.00 \\
\hline Unaccounted-for hours $^{\mathrm{e}}$ & 5.30 & & $\underline{5.38}$ & & 6.94 & \\
\hline Total & $\overline{168}$ & & $\overline{168}$ & & $\overline{168}$ & \\
\hline
\end{tabular}

Legend: Std. Dev. - Standard Deviation

a. Household chores hours were the sum of the average hours each schoolchild in the above three categories spent per week on cleaning, cooking and childcare

b. Leisure hours were average hours available per week for ease and relaxation free from responsibilities.

c. School hours were average hours per week dedicated for education. This included time spent walking to and from school, time in school and time spent on school homework plus private studies at home.

d. Unaccounted-for hours referred to average non-explained time spent per week on any unforeseen activity including petty trading (street vendor) or the like-nature business.

Girls and boys spent, on average, the same number of hours per week in school activities in all environmental conditions. On average, they dedicated 60 hours per week on education. This included time spent walking to and from school, time in school and time spent on school homework plus private studies at home. There were some minor variations of time spent on 
other activities like collecting scarce environmental products and/or grazing, agriculture and household chores depending on the gender biased nature of the activity and the environment where the activity was taking place. Because of these slight variations of time use in other activities apart from education, we consequently notice some variations in leisure hours per week amongst the genders. While boys had, on average, more leisure hours in both non-degraded and medium-degraded environments, they had less leisure hours in severely-degraded environments. Surprisingly, a cross-sectional check of time use per week on scarce environmental product collection and/or grazing activities reveals that households in all environmental conditions lose comparatively more hours worked when they sent boys to school than when they sent girls. Likewise, households in almost all environmental conditions (but especially in the non-degraded and the medium-degraded areas) lose comparatively more hours worked on household chores when they sent girls to school than when they sent boys. Reasons as to why boys spent relatively more time for grazing and fuel wood collection in all environmental conditions were clear because grazing predominantly was a male job and fuel wood was scarce even in the non-degraded environment due to reforestation programs accompanied with the prohibitive by-laws causing adult females to walk long distances to collect the stuff. For security reasons then, male children were preferred to accompany their female parents on the way to and from the open access. However, it is not clear why boys in comparison to girls spent more time in water-fetching activity in all environmental conditions. Probably the same protective role to and from the water source contributed to this realization as girls made themselves more available at home for domestic chores.

The time use profile was collected for schoolboys and schoolgirls in different cohorts between 6 and 19 years of age. Figure 1 shows the distribution of schoolchildren interviewed with respect to their age. Not surprisingly, as children got older, those who attended school tended to spend more time in school and on school work while those with tender ages might have not enough strength to offer required labour force in various examined activities. This explains the nearly normal distribution curve presented in Figure 1. The majority of the schoolchildren under survey were between 10 and 15 years old. This trend did not differ according to the child's gender.

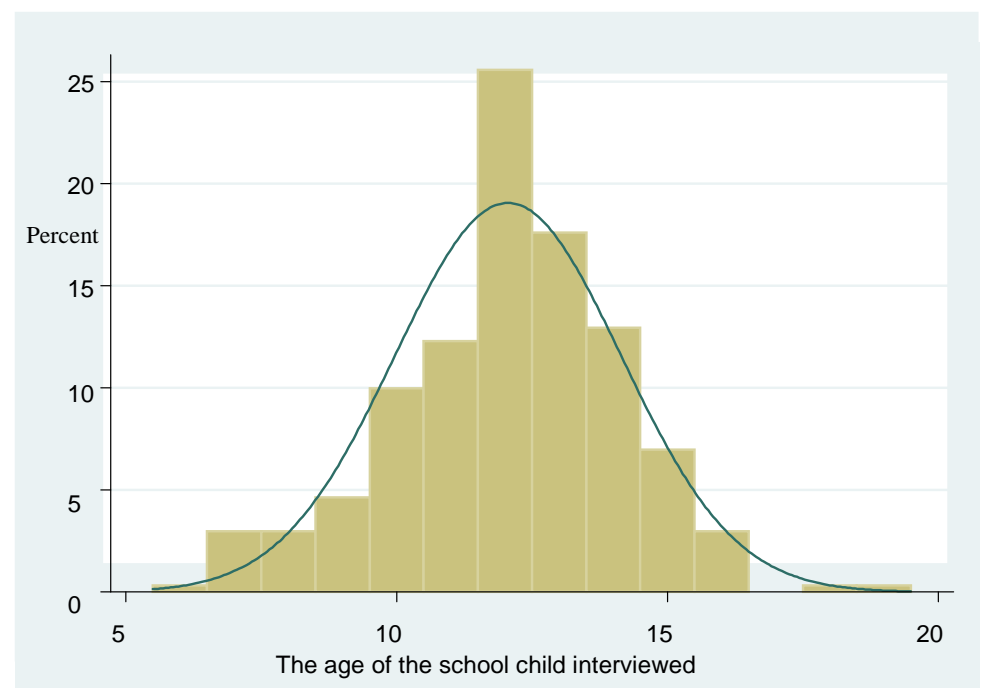

Figure 1: Age distribution of schoolchild

In defining child labour, the International Labour Organization (ILO, 1997a,b) considered a 
person as a child if he/she was under 14 years of age. For our analysis, we selected an age range of 6-19 years. The justification of taking this age cohort was as follows: According to the education system of Tanzania, children in the 15-19 years age range should be at the end of secondary school or at the beginning of higher secondary school (Al-Samarrai and Tessa 1998). However, the data set suggests that there were some children in the $15-19$ years age group who were still at primary school. It was not surprising for a country like Tanzania, where late enrolment, especially in rural areas, was common. Thus including children of 15 to 19 years old allowed us to consider late entry and grade repetition. Moreover, we observed several cases where children under 20 years old lived with their parents, except daughters who tended to join their husbands' families after marriage. All schoolchildren aged 6-19 years included in this analysis had both their father and mother living together in the same house. This sample was part of the 88 percent of the children of various ages, educational and occupational backgrounds who still resided in the homestead as sons/daughters of their own parents. The remaining percentages, which were excluded in our analysis, were grand children ( 9.3 percent), adopted/step children (1.3 percent) and niece/nephew (1.4 percent) of household heads.

Likewise, although official enrolment age in Tanzania was 7 years, we still have a minimum age of 6 years in our data set because there were children who started school at age 6. For the estimation of child labour in agricultural, household, environmental product collection and/or grazing activities, 6 years old might be considered extreme. But it was common in rural Pare and elsewhere in the countryside for young children to participate. A survey by Bangladesh Institute of Development Studies (BIDS 1977-78), for instance, reports that the rural children in Bangladesh start their economically productive life from 5 years of age (Salauddin, 1981). Our data in rural Pare also shows that there was one boy of age 6 who combined school with other work. For primary school late entry cases, our data set records 23.6 percent of the schoolchildren who started class 1 at the age of 8, 19.8 percent at the age 9, 4.3 percent at the age of 10 and 0.7 percent at the ages of 11 and 12 each, respectively. Our sample shows that only 51.2 percent of the attending schoolchildren started class 1 at the right age of 7 as required by the education system in Tanzania. The reasons of the late entry as stipulated by the pupils themselves are presented in Table 2.

Table 2: Reasons for primary school late entry

\begin{tabular}{lrr}
\hline Reason & Frequency & Percent \\
\hline Illness & 44 & 14.6 \\
Work at home & 15 & 5.0 \\
Work on the farms & 9 & 3.0 \\
Collection environmental products and/or grazing & 15 & 5.0 \\
School crowded & 60 & 19.9 \\
Inability to meet direct school costs, e.g. school uniforms and stationery & 4 & 1.3 \\
Not applicable (entry on time) & $\underline{154}$ & $\underline{51.2}$ \\
Total & $\mathbf{3 0 1}$ & $\mathbf{1 0 0}$ \\
\hline
\end{tabular}

Table 2 shows that the main reasons for late entry are: school being crowded (19.9 percent), 
illness (14.6 percent), work at home (5.0 percent) and collecting scarce environmental product and/or grazing (5 percent).

\section{Model Specification}

\subsection{Theoretical framework}

At the household level, education can be viewed both as an investment and as consumption good (Al-Samarrai and Reilly, 2000).

Education is an investment good because parents invest in their children's education so that their children and grandchildren will have better life chances, and because they enjoy having literate and educated children. Parents also invest in their children's education to ensure that their offspring will be best placed to support them in later life (Al-Samarrai and Tessa 1998). A household production function approach has been widely adopted in the literature to model school decisions made at the household level (see Tansel, 1993; Durasaimy, 1992; Strauss and Thomas, 1995; Glewwe, 2002). These models imply that there is an optimal investment in education for each child equating the present value of the expected marginal costs and benefits to the household. Costs are incurred throughout the duration of a child's schooling and include direct costs (e.g., school contributions and stationery) and the opportunity costs of a child's time (e.g., household work and farm activities foregone while at school). The benefits to the parents of educating their children depend on a number of factors, including the rate of expected remittances from their children when they leave home, the probability that their children will find work, and the time preferences of the household members. Although the optimal level of investment in education is determined by each household, the presence of constraints implies that the optimum amount of education may be unattainable. For example, the monetary costs of education are incurred before many of the monetary benefits are realized. Some households may not have the resources available to finance the initial costs of education for some or all of their children and, through lack of collateral, may be unable to borrow the necessary resources from capital markets. This implies that the educational attainment will be related to other household characteristics, such as household income and the levels of parental education.

Education can also be seen as a consumption good, in that it can directly enhance parents' utility and there may also be non-monetary benefits to education for the acquiring child (i.e., the child's current utility may be enhanced by going to school, and also by not having to work). Schultz (1963) describes the consumption benefits of education as divisible into three components: an investment component which results in an increase in an individual's measured wealth; a present consumption component such as the utility currently derived, say, from attending class; and a future consumption component which results from the fact that education improves one's ability to consume other goods later in life. A considerable amount of research has been done on the use of education in non-market activities. Michael (1973a), for example, claims that more educated individuals consume other commodities, such as reading, more than their less-educated counterparts. Liebowitz (1974) finds that an increase in a mother's level of education is associated with a higher-measured intelligence quotient (IQ) for her child. In the area of family planning, Michael (1973b) has found that more educated 
individuals are better contraceptors and are less likely to experience an unwanted birth. Benham (1974) finds that an increase in a woman's education is associated with higher earnings on the part of her spouse, given his education. That is, an educated woman finds a higher earning spouse. These examples show that education is associated with many aspects of an individual's behaviour in addition to its impact on his earnings capacity.

When education is seen in this way, the households' preferences for educated children may be an important factor in the decision to send children to school or not. This is likely to be related to the level of education of the parents. Preferences for schooling of boys and girls are formed in the context of social and cultural norms, and it is likely that preferences will be gender specific and household attributes will have a differing impact on the schooling decision for boys and girls.

The above considerations suggest a number of explanatory variables that might influence primary school attainment. These variables include, inter alia, parental characteristics, household income levels, household size, cost of schooling in monetary and opportunity terms, individual characteristics like gender and age, and location variables. Location variables include the status of environmental quality where the household is situated. Some of the studies (Note 2) adopted such an approach in their analysis of primary schooling in Tanzania. Other studies (Note 3) also preferred the same approach in their analysis of primary schooling elsewhere in Africa. However, these studies excluded the environmental degradation phenomenon.

We adopt this framework here but with an emphasis on exploring the effects of environmental quality status of the area where the household is situated. There is a fundamental reason why environmental degradation status could result in different education outcomes among schoolchildren. We think that schoolchildren in different environmental degradation situations may be victimized differently with regard to their time use patterns in different activities including scarce environmental product collection and/or grazing, farming and domestic work, which would result in poor school progress. A key issue, therefore, is to examine, inter alia, the extent to which variations in environmental degradation are explaining disparities in primary school progress.

\subsection{Empirical specification}

The variable indicating school progress in this study is referred to as "educational attainment" implying progressing at the right age for class. In the literature (Note 4), one frequently used measure of school attainment when the sample is younger and still at school is SAGE (Schooling-for-Age or Grade-for-Age). SAGE is calculated using the procedure proposed by Patrinos and Psacharopoulos (1997) given as Grade-for-age $=100^{*}\left[\frac{\text { Gradeor } \text { class }}{\text { Age }-E}\right]$ where $E$ represents the country-specific usual school entry age (which is seven years in Tanzania). SAGE will therefore measure school attainment relative to age. A score of less than 100 indicates that the child is falling behind in education. Consequently, all those with a score under 100 are considered as having below normal progress in the school system. The formula for SAGE as proposed by Patrinos and Psacharopoulos (1997) presents, however, several 
issues when using our data on young children. For children who are in their first year of schooling, a strict interpretation of SAGE will give an infinite value since the denominator equals zero (since Age $-\mathrm{E}=0$ ). Further, if a child starts school before he/she reaches the minimum age, then SAGE potentially can be greater than 100 . In this case then, $E=7$ cannot be used for the entire sample in constructing SAGE which automatically leads to loss of information. If $\mathrm{E}=7$ is used, then SAGE will take negative values for six year-old children, and infinite values for seven year-old children. For the purpose of estimation therefore, in our study, the formula for educational-attainment variable is modified into a discrete ordered variable, which is obtained using the following formula:

$$
S A G E=(\text { Grade or class }- \text { Age })+(E-1)
$$

Because the compulsory entry age in Tanzania is 7, the educational attainment formula becomes $S A G E=$ Grade-Age +6 . It follows that if $S A G E=0$ implies "on time" school progress; $S A G E>0$ "ahead" of normal school progress; and $S A G E<0$ indicates "falling behind".

The literature (Note 5) also recognizes schoolchildren as producers and consumers of commodities who participate in household and agricultural production as well as in their own schooling and leisure. Schooling is a commodity whose grade attained (SAGE) is subject to time allocated to education $T_{c}$, household characteristics that affect child education e.g. ethnicity $Z_{c}$, individual characteristics like gender, age, age squared, parents' educational level, occupation, etc. $F_{c}$, household income $I$, household size $H$, market-priced school goods $G_{c}$, environmental quality $E$, and the interactions (Note 6). The square of the age is included to account for any non-linear age effects. Equation (1) is proposed:

$$
S A G E=c\left(T_{c}, Z_{c}, F_{c}, I, H_{c}, G_{c}, E, E^{*} I\right)
$$

Where the subscript $c$ is restricted to characteristics that affect school attainment exclusively.

The environmental quality $E$ may affect the children's education through its effect on the productivity of time in the household production function. For instance, if the environment is more degraded, children will have to spend more time on environmental product collection and/or grazing at the cost of their schooling. That is, the number of hours that children spend on resource collection and/or grazing is associated with a reduced likelihood of school attendance, supporting the hypothesis of resource collection work having a negative influence on schooling.

Household size $H$ is included in the specification to capture possible substitutes for child labour. Nankhuni (2004) observed that the presence of other active family members in the household is associated with fewer hours of resource collection work for schoolchildren. This suggests that a larger number of household members beyond school age help to relieve the work burden on school-age children and thus increase the probability of attending school. In 
the household size variable, we also include the gender of the members. We believe that the number of women in the household increases the likelihood of children to attend school. This suggests that female household members, who are principally involved in household responsibilities, tend to reduce the burden of household work on school-age children. This effect was also observed in Côte d'Ivoire by Coulombe (1998), for girls in Peru by Levison and Moe (1998) and for girls in Egypt by Assaad et al. (2001). Likewise, adult males, who are principally responsible for grazing might reduce the burden of grazing on school-age children, especially boys, for those households that keep cattle, thus increasing children's school attendance.

Household characteristics $Z_{c}$ also affect the likelihood of a child participating in natural resource collection work and the intensity of this work (Nankhuni 2004). Ethnicity, for example may influence the probability of whether a child of particular gender would progress well at school or not. Some tribes in Tanzania may not value the education of girls highly and therefore may not seriously invest in their human capital formation. The idea behind is that girls will get married and may shift to another clan. Investing in the education of girls, in this case, would benefit the would-be husband's clan. Schoolgirls originating from clans of this mentality may have a greater probability of working long hours collecting environmental products and/or grazing, performing domestic chores and working at fields as a sort of training for their physical capability of maintaining their would-be families once they get married.

No information on market-priced school goods $G_{c}$ is reported in the data. As a result, the effects of direct cost of schooling is implicitly reflected in the household income variable $I$. A household may be forced to keep the children away from school because its income is close to the subsistence level (Jensen and Nielsen 1997). On the other hand, we expect that relatively wealthier households are less resource constrained in meeting direct school costs, which makes it easy for their children to attend school and probably progress at school. Connected to the household income is the interaction of the environmental degradation situations and the logarithm of the total household income. In the estimations, we include the interaction of the environmental degradation situations and the logarithm of the total household income to test whether the effects of household income are influenced by the level of environmental degradation, even in education regard.

Excluded from the list of variables, although deemed desirable, is school quality. School quality data is unavailable from this survey. However, Nankhuni (2004), showed that children living in areas in Malawi where schools are relatively poorly stocked (as reflected by the number of school-age children per teacher) are not necessarily less likely to attend school, implying that school quality measured in this way may not be the most important issue in school attendance. However, we still believe that the variable might affect educational attainment in South Pare and its omission is regretted.

The familial relationship within the household is also considered. This is because we believe 


\section{Macrothink}

that familial relationship is posited to influence educational outcomes. Burke and Beegle (2004), for example, proved that children residing with their parents may face different outcomes than foster children and orphans. Foster children and orphans are potentially disadvantaged in many ways, although the evidence for this varies across countries (Ainsworth et al, 2002). Foster and orphan children have been found to lack proper nutrition, have less access to health care, work longer hours and receive less schooling than the family's own children (Ainsworth, 1996; Bledsoe et al., 1988). We control for foster and orphan status by selecting school-age children who live with their biological parents.

\section{Estimation Strategy}

SAGE, our dependent variable, is an ordinal variable, which indicates a ranking of school attainment. Since the values of such an ordered school progress are arbitrary and are a function of a set of explanatory factors as described in equation (1), we use ordered probit estimation techniques. The following specification is used:

$$
C_{i}^{*}=\beta^{\prime} z_{i}+\varepsilon_{i}, \quad \varepsilon \sim N(0,1), \quad i=1, \ldots, N
$$

where $C_{i}^{*}=$ the latent measure of educational attainment

$z_{i}=$ a vector of explanatory variables describing the school attainment

$\beta=$ a vector of parameters to be estimated, and

$\varepsilon_{i}=$ a random error term (assumed to follow a standard normal distribution)

Figure 3 illustrates the correspondence between the latent, continuous underlying school attainment variable, $C_{i}^{*}$, and the observed educational progress, $C_{i}$.

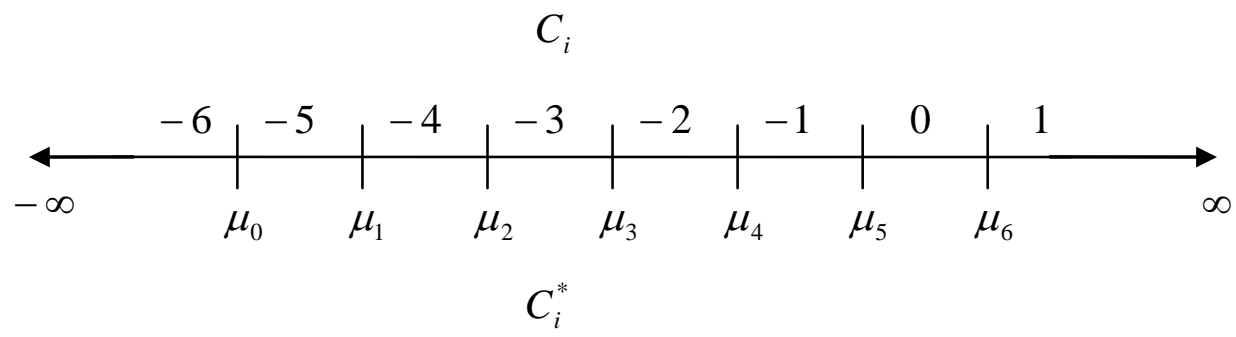

Figure 2: Relationship between latent and coded educational attainment variables

The observed ordinal school attainment variable, $C_{i}$, takes on values of -6 through +1 in the following scheme:

$$
C_{i}=j \Leftrightarrow \mu_{j-1}<C_{i}^{*} \leq \mu_{j}
$$


where $j=-6$ through +1 . This range of values for $j$ is derived by fitting the corresponding survey data in the educational attainment (SAGE) formula described earlier. The eldest schoolchild in our sample, aged 19 years old was in grade (class) 7; while the youngest schoolchild was 6 years old, being in grade 1. Employing the SAGE formula, we obtain -6 and +1 , respectively.

In the pursuit of completeness, we define $\mu_{-1}=-\infty$, and $\mu_{m}=+\infty$. We are concerned with how changes in the predictors translated into the probability of observing a particular ordinal outcome in the range of -6 to +1 .

Considering the probabilities of each ordinal outcome, the generic form is:

$$
P\left[C_{i}=j\right] \quad=\Phi\left(\mu_{j}-\beta^{\prime} z_{i}\right)-\Phi\left(\mu_{j-1}-\beta^{\prime} z_{i}\right)
$$

For $j=m$ (the "highest" category), the generic form reduces to

$$
\begin{aligned}
P\left[C_{i}=m\right] & =\Phi\left(\mu_{m}-\beta^{\prime} z_{i}\right)-\Phi\left(\mu_{m-1}-\beta^{\prime} z_{i}\right) \\
& =1-\Phi\left(\mu_{m-1}-\beta^{\prime} z_{i}\right) .
\end{aligned}
$$

Since $m=1$, then

$$
\begin{aligned}
P\left[C_{i}=1\right] & =\Phi\left(\mu_{1}-\beta^{\prime} z_{i}\right)-\Phi\left(\mu_{0}-\beta^{\prime} z_{i}\right) \\
& =1-\Phi\left(\mu_{0}-\beta^{\prime} z_{i}\right) .
\end{aligned}
$$

where $i$ is a schoolchild and $\Phi($.$) is the standard normal cumulative distribution function.$

The interpretation of this model's primary parameter set, $\beta$, is as follows: positive signs indicate higher school attainment as the value of the associated variables increase, while negative signs suggest the converse (see Greene 2000).

\section{Estimation Results and Discussion}

Three separate sets of results are given in the upper part of Table 3 for schoolgirls (Column 1), schoolboys (Column 2) and for the pooled regression including a gender dummy (Column 3). The lower part of Table 3 shows Greene's post-estimation parameterization which provides both the coefficient estimate and the standard error of the thresholds $\mu_{i}$. 


\section{Macrothink}

The probability of educational attainment at primary school, in all regressions, was found to be significantly associated with age, age-squared, and the mother's secondary education. The formal employment status of the mother being in a government office significantly affected the probability of educational attainment of both the schoolgirl and the schoolboy in different ways, but not in the pooled sample estimates. The household belonging to the Sambaa tribe, as compared to other tribes, significantly decreased the probability of schoolgirls progress at primary school. The basic literacy of the mother at the primary education level, cropped land size, and the interaction term of medium-degraded environment and household annual income increased, at a lower significance level, the probability that schoolboys would progress at school. Interestingly, in severely-degraded environments as compared with non-degraded areas, the probability of girls' progress at school was significantly lower. However, the environmental degradation situation neither had significant impact on schoolboys' educational attainment nor for the pooled sample of schoolgirls and schoolboys. Thus, for our sample, environmental degradation and time spent collecting scarce environmental products proxied by the average kilograms of fuel wood and litres of water used in the households per week had no significant effect on the school attainment of the pooled sample. Attempts were made to include the corresponding hours from the field data for the respective product collecting activities in the regression. However, the results remained insignificant as it was the case with the proxies. This is not surprising, however, because from the descriptive statistics, the girls and boys spent, on average, the same number of hours per week in school activities across the environmental conditions. Though the descriptive statistics showed some minor variations of time spent on other activities like collecting scarce environmental products and/or grazing, agriculture and household chores depending on the gender biased nature of the activity and the environment where the activity was taking place, the slight variations of time use in other activities (apart from education), affected negatively the leisure time of schoolgirls especially in the non-degraded and medium-degraded environments rather than the educational attainment of either gender.

Both the age of the schoolchild and the age-squared are statistically significant in all Columns. This implies that there was a significant non-linearity in the effect of age of the child on school attainment, decreasing after the age of 6.5 years. That is, the older the child, the more (s)he lagged behind. We obtained similar effects for the gender specific estimates. The descriptive statistics presented earlier supports this result. In our sample, we had schoolchildren in the 15 - 19 years age group who were still at primary school, suggesting that there was late entry and grade repetition, and thus not enough progress in the grade-for-age school attainment. Some schoolchildren in the $7-13$ age cohort were not in their proper grades, indicating that they were lagging behind in educational attainment. Table 2 showed that only 51.2 percent of the attending schoolchildren started grade 1 at the right age of 7 as required by the educational system in Tanzania. However, the environmental degradation situations did not impact much on these delays in school attainment because the environmental products collection and/or grazing, work at home, and work on the farms, each contributed less than or equal to 5 percent only to total primary school late entry, negatively affecting the girls (see Table 3, Column 1). 
Table 3: Estimation results: Ordered Probit: Dependent variable: Primary school attainment

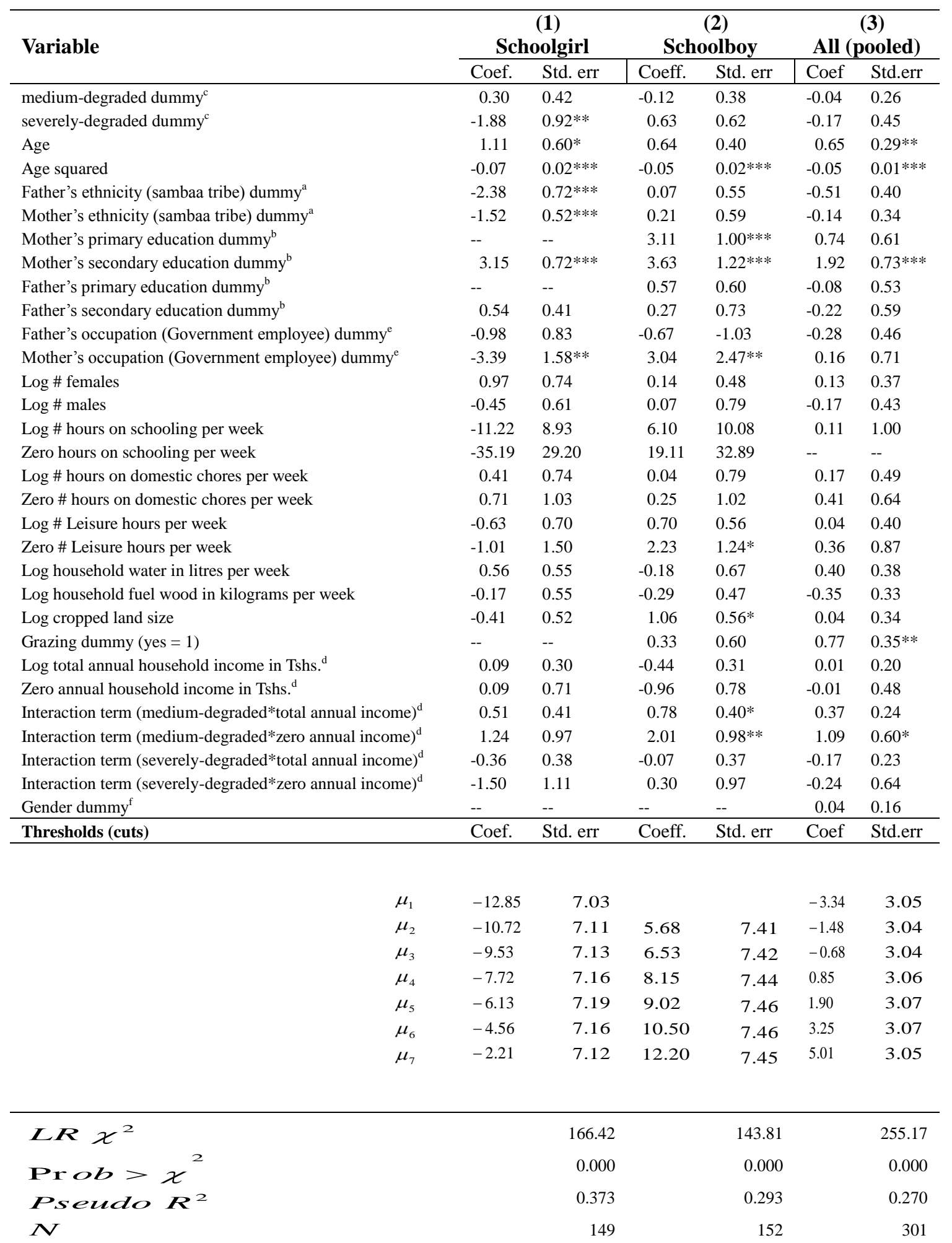

Post-estimation: Greene's parameterization

\begin{tabular}{lllllll}
\hline Thresholds & Coef. & Std. err & Coeff. & Std. err & Coef & Std.err \\
\hline
\end{tabular}




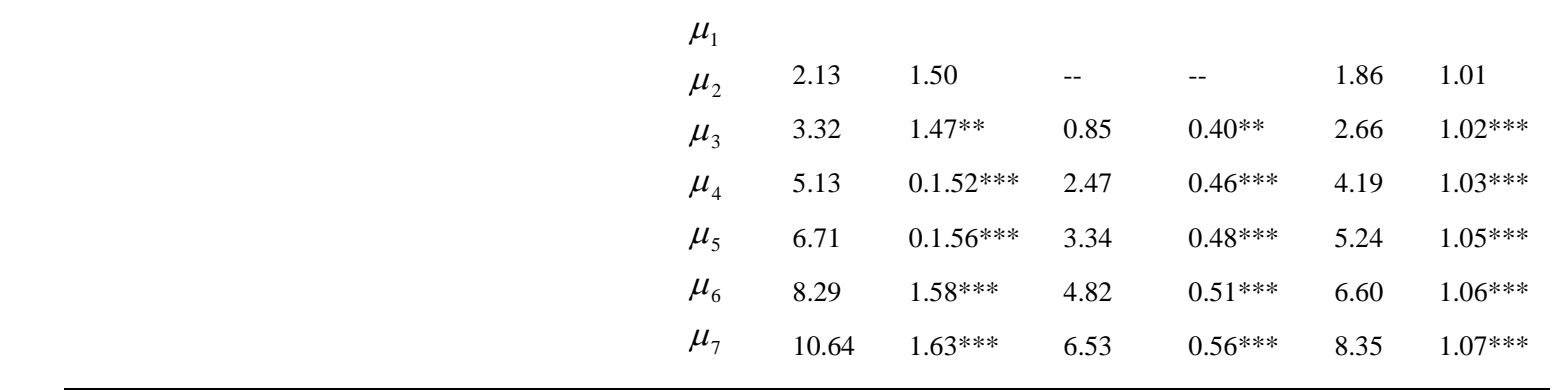

Legend:

$>$ Because of the zero hours (or zero extra income) if either a schoolchild did not participate in that particular work (or if the household did not have income); then the following technique was applied:

[a] (Dummy x log (hours), or (Dummy x log (income))

[b] (1 - Dummy)

Where if not observed $\log$ (hours) or $\log$ (income) $=0$. Dummy $=1$ if the child was participating ( or if the household had income) and 0 if else.

$>\quad * P<.1, \quad * * P<.05, \quad * * * P<.0$

$>\quad{ }^{\mathrm{c}}=$ reference category: Non-degraded.

${ }^{\mathrm{b}}=$ reference education level is " illiteracy"

$>\quad \mathrm{a}=$ reference tribe is "other".

$\mathrm{e}=$ reference occupation is "other"

${ }^{\mathrm{f}}=$ reference gender is the schoolboy

$>{ }^{\mathrm{d}}=$ income, as defined in the text, is the total household income from all sources minus the monetary value of the home consumption of the survey crops.

The mother's literacy level generally had a positive and statistically significant effect on the educational attainment of the schoolchildren regardless of their gender. While the mother's secondary education significantly increased the probability of both the girls' and the boys' progress at school, the basic literacy of the mother at the primary education level significantly increased the educational attainment of the boys only. The effects were quite strong. Though the father's literacy had no effect on either boys or girls, nevertheless, the results support the findings of Al-Samarrai and Tesha (1998) that education is an investment good in the sense that the parents (in our case, mothers) invested in their children's education so that their children would have better life chances and so their offspring would be best placed to support them in later life. The schoolboys' education was favoured even by the mother with just a primary education because culturally, the boys are coheirs of the family properties. Thus, education would place them in an outstanding position to manage prudently the inheritance afterwards. Likewise, in this regard, the parents' utility would be enhanced. That is, the parents (especially the mother, in our case) considered education as an investment good. The results support the findings by Behrman and Wolfe (1987), King and Lillard (1987), and Maitra (2003) that the mother's education generally has a strong influence on the education of the children.

On the other hand, however, as would be expected, the cultural preferences in terms of the attitudes towards education had a significant negative effect on girls' educational attainment. Girls belonging to the Sambaa ethnicity compared to the other tribes living in South Pare (like the Pares and Chaggas), showed significantly lower probability of grade-to-age educational attainment. This implies that the Sambaa tribe probably did not value human 
capital formation of girls highly as the girls would get married and might shift to the would-be husbands' clan who, in turn, would benefit from the educational investment previously done by the girls' parents.

The other result worth noting is the mother's occupation. The formal employment status of the mother at a government office significantly decreased the probability of educational attainment for schoolgirls, whereas the probability of educational attainment for schoolboys was significantly enhanced. Taking the ceteris paribus condition, the absence of the mother at home during the day due to employment obligation, would leave the household chores unattended if the schoolgirl in the household would not replace her mother. Thus, the households would loose comparatively more hours worked on household chores if they sent girls to schools than when they sent boys. If they decided not to send the schoolgirl to school to fill in the gap of the mother's day absence at home, then, the girls would be affected much more than the boys in educational attainment.

The cropped land size, and the interaction term of the medium-degraded environment and the household annual income increased, at a 10 percent level of significance, the probability that schoolboys would progress at school. Household income comes mainly from the sales of agricultural produce excluding own-household consumption. The income was used to meet the household cash demands in several respects, including the direct costs of schooling. Since there was no information on market-priced school goods reported in the data, the direct cost of schooling was implicitly reflected in the household income. An increase in the household income would, in turn, enhance indirectly the educational attainment of the child. Since the human capital formation of boys was favoured in the area, then, its effect would significantly increase the probability of school attainment for them. The agricultural produce, which was the main source of household income, was highly dependent on the cropped land size. It is no wonder then, that the cropped land size too, though at a lower degree, had a significant impact on the increase of the probability that the schoolboy would progress at school.

Lastly, Greene's parameterization (lower part of Table 3) shows that all point estimates, except $\mu_{1}$ for both schoolgirls' and the pooled regressions, were highly significant. The results suggest that the determination of the likely school attainment classification for a particular schoolchild in our analysis suited the data, and was statistically meaningful. $\mu_{1}$ was not significant for the schoolgirls and in the pooled regressions because there was just one observation in the dataset of a schoolchild who was falling behind for 6 years in educational attainment. That particular child was a girl. This explains why the thresholds for the boys' regression were only 6 because the highest delay in educational attainment was 5 .

\section{Conclusion}

Our interest in this paper was to test whether school attendance and progress of children in rural primary schools, with respect to their gender, was inversely affected by deteriorating environmental resources. Our findings show that there were other factors that significantly affected the probability of school attainment for the schoolchildren apart from the 
environmental degradation situations. Environmental degradation, in all estimates except for the schoolgirls in severely-degraded environment, did not have a significant impact. Reasons discussed ad hoc in Section 5, and now put together here, were mainly two. Firstly, girls and boys spent, on average, the same number of hours per week in school activities across environmental conditions. Secondly, the reasons mentioned indicate deteriorating resources like environmental products collection and/or grazing, work at home, and work on the farms, each contributed only marginally (less than 5 percent) to total primary school late entry. In the regression, those factors negatively affected the girls only.

Furthermore, though all three regressions in Table 3 had satisfactory explanatory power for educational attainment, the Pseudo-R2 however might be improved in future research by adding school crowdedness, illness, bad weather, et cetera. These factors, together with "other" reasons suspected to include street petty trading, and poor quality of some primary schools, were equally important factors for late school entry, and consequently, for the delay in the grade-to-age school attainment (see Table 2). Hence we suggest that the educational attainment in South Pare was also associated with bad health (illness), school absenteeism due to petty trading and/or informal casual labour, and poor quality of some primary schools. By poor school quality we refer to the low teacher-pupils ratio (that is, shortages of teachers), teachers' incompetence, and the shortages of learning facilities such as books, school desks, proper classrooms, etc., all of which in the Tanzanian context, are funded by the local government assisted with the central government. The policy makers therefore, in their attempt to improve educational attainment and human capital formation at primary level should, as well, focus on these other relevant factors excluded from our model. For either the local or central government to be able to fund the learning facilities, the growth of the economy is an important aspect. The policy makers thus need to make overall strategies that would guarantee high growth rate of the economy in both the medium and long term, which in turn, will increase the budgetary allocations to the education sector to cater for both recurrent and capital expenditures. At the moment, the government resources committed to education are low (Mbelle and Katabaro 2003). Moreover, the non-government sector may also be enticed into investing in education through attractive fiscal incentives.

\section{References}

Akabayashi, H., and G. Psacharopoulos (1999). The Trade-off between Child Labour and Human Capital Formation: A Tanzanian Case Study. Journal of Development Studies, 35 (5):120-140. http://dx.doi.org/10.1080/00220389908422594

Ainsworth, M. (1996). Economic Aspects of Child Fostering in Cote d'Ivoire. Research in Population Economics, 8: 25-62.

Ainsworth, M., K. Beegle and G. Koda. (2002). The Impact of Adult Mortality on Primary School Enrolment in Nortwestern Tanzania. Africa Region Human Development Working Paper 23961, Washington DC: World Bank.

Al-Samarrai, S., and P.Tessa. (1998). Educational attainments and household characteristics in Tanzania'. Economics of education review, vol. 17, no. 4, pp. 395-417. 


\section{I Macrothink}

International Journal of Education ISSN 1948-5476 2012, Vol. 4, No. 1

Al-Samarrai, S., and B. Reilly. (2000). Urban and Rural Differences in Primary School Attendance: An Empirical Study for Tanzania. Journal of African Economies, Vol. 9, Number 4, pp. 430-474. http://dx.doi.org/10.1093/jae/9.4.430

Assaad, R., D. Levison, and N. Zibani. (2001). The Effects of Child Work on School Enrollment in Egypt. Paper Presented at Workshop on the Analysis of Poverty and its 183 Determinants in the Middle East and North Africa (MENA) Region, July 31 . August 1, 2001, Sanaa, Republic of Yemen.

Becker, G. S. (1993b). Human Capital: A Theoretical and Empirical Analysis, with Special Reference to Education, Third ed. Chicago: University of Chicago Press.

Behrman, J.R., and B.L. Wolfe. (1987). Investment in Schooling in Two Generations in Pre-revolutionary Nicaragua: The Roles of Family Background and School Supply. Journal $\begin{array}{llllll}\text { of Development } & \text { Economics, } & 27(1-2), & 395 & - & 419 .\end{array}$ http://dx.doi.org/10.1016/0304-3878(87)90024-1

Benham, L. (1974). Benefits of Women's Education within Marriage. J.P.E., 82, no. 2, pt. 2 pp.57-71.

Binder, M., and D. Scrogin. (1999). Labor Force Participation and Household Work of Urban School Children in Mexico: Characteristics and Consequences. Journal of Economic Development and Cultural Change, 48 (1):123-154. http://dx.doi.org/10.1086/452449

Birdsall, N., and F. Orivel. (1996). Demand for Primary Schooling in Rural Mali: Should User Fees Be Increased? Education Economics, v4 n3 p279-96.

Bledsoe, C.H., D.C. Ewbank and U.C. Isiugo-Abanahie. (1988). The Effects of Fostering on Feeding Practices and Access to Health Care Services in Sierra Leone. Social Science and Medicine, 27 (6) 727-636. http://dx.doi.org/10.1016/0277-9536(88)90011-1

Burke, K., and K. Beegle. (2004). Why children aren't attending school: The case of north-western Tanzania. Journal of African Economics, vol. 13, number 2, pp. 333-355.

Caldwell, J., and P. Caldwell. (1990). High Fertility in Sub-Saharan Africa. Scientific American, 262 (May) 118- 125. http://dx.doi.org/10.1038/scientificamerican0590-118

Canagarajah, R. S., and H. Coulombe. (1997). Child Labor and Schooling in Ghana. Working Paper Series, No. 1844. The World Bank, Washington, D.C.

Coulombe, H. (1998). Child labour and education in Cote d'Ivoire. World Bank. Unpublished.

Duraisamy, P. (1992). Gender, intrafamily allocation of resources \& child schooling in South India. Discussion Paper No. 667. Yale University, New Haven, CT.

Glewwe, P. (2002). Schools and Skills in Developing Countries: Education Policies and Socio-economic Outcomes. Journal of Economic Literature, 40 (2): 436-482. http://dx.doi.org/10.1257/002205102320161258 
Greene, W. H. (2000). Econometric Analysis. Fourth edition. New Jersey, Prentice Hall.

Grootaert, C. (1999). 'Child Labor in Cote d.Ivoire' in Grootart, C. and H. Patrinos eds., The Policy Analysis of Child Labor: A Comparative Study St. Martin Press, New York.

Grootaert, C., and H. Patrinos. (1999). The Policy Analysis of Child Labor: A Comparative Study. Journal of Economic Literature 40(2), 402-435.

Ilahi, N. (2001b). Children's Work and Schooling: Does Gender Matter? Evidence from Peru LSMS Panel Data'. World Bank Policy Research Working Paper No. 2745. The World Bank, Washington, D.C.

ILO. (1997a). Combating the Most Intolerable Forms of Child labour: A Global Challenge in the Report on Combating the Most Intolerable Forms of Child Labour: A global challenge', Child Labour Conference, Ministry of Social Affairs and Employment, The Hague. Netherlands.

ILO. (1997b). Statistics on Working Children and Hazardous Child Labour'. Brief, Bureau of Statistics, ILO, Geneva.

Jensen, P., and H.S. Nielsen. (1997). Child labour or school attendance? Evidence from Zambia'. Journal of Population Economics, Volume 10, Number 4; Springer Berlin / Heidelberg. Pp. $407-424$.

Khanam, R., and R. Russell (2005), Child work and other determinants of school attendance and school attainment in Bangladesh. Munich Personal RePEc Archive. Paper \# 9397.

King, E.M., \& AND 1. Lillard. (1987). Educational Policy and Schooling Attainment in Malaysia and the Philippines. Economics of Education Review, 6(2), 167 - 81. http://dx.doi.org/10.1016/0272-7757(87)90050-1

Lavy, V. (1996). School supply constraints and children's educational outcomes in rural Ghana. Department of Economics, Hebrew University of Jerusalem, Mount Scopus, 91905, Jerusalem, Israel.

Levison, D., and K.S. Moe. (1998). Household Work as a Deterrent to Schooling: An analysis of Adolescent Girls in Peru. Journal of Developing Areas, 32 (3):339-356.

Levison, D., K.S. Moe, and F.M. Knaul. (2001). Youth Education and Work in Mexico'. World Development, 29 (1):167-188. http://dx.doi.org/10.1016/S0305-750X(00)00090-5

Maitra, P. (2003). Schooling and Educational Attainment: Evidence from Bangladesh,. Education Economics, 11(2), 129-1953. http://dx.doi.org/10.1080/09645290210131665

Mason, A.D., and S. R. Khandker. (1996). Household Schooling Decisions in Tanzania', manuscript, Poverty and Social Policy Department, Human Capital Development, Washington, DC: World Bank.

Mbelle, A., and J. Katabaro (2003). School Enrolment, Performance and Access to Education in Tanzania. Research Report no. 03.1 submitted to Research on Poverty Alleviation 
(REPOA). Mkuki nad Nyota Publishers LTD. Dar es Salaam. Tanzania.

Michael, R. (1973a). Education in Non-Market Production. J.P.E., 81, no. 2, pt. 1 pp. 306-27. (1973b). Education and the Derived Demand for Children. J.P.E., 81, no. 2, Pt. 2 pp.128-164.

Muller, E. (1976). 'The Economic value of Children in Peasant Agriculture' in R.G. Ridder eds. Population and Development: The search for selective interventions. Baltimore: Johns Hopkins University Press.

Nankhuni, F. (2004). Natural resource-collection work and children's schooling in Malawi. Agricultural Economics, 31 (2004) 123-134. http://dx.doi.org/10.1016/j.agecon.2004.09.022

Orazem, P., and Gunnarsson, L. V. (2004). Child labour, school attendance and performance: A review. Working Paper \# 04001. Department of Economics, Iowa University.

Orazem, P., V. Gunnarsson, and G. Sedlacek. (2003). Changing Patterns of child labour around the world since 1950: the role of poverty, parental literacy and agriculture, in P.F. Orazem and G. Sedlacek (eds) Eradicating child labour in latin America in the 90s: The promise of Demand Side Interventions, (Washington, D.C., World Bank and IDB).

Patrinos, H.A., and G. Psacharopoulos. (1997). Family Size, Schooling and Child Labour in Peru. An Empirical Analysis. Journal of Population Economics, 10:387-405. http://dx.doi.org/10.1007/s001480050050

Psachalopoulos, G. (1997). Child Labour versus Educational Attainment: Some Evidence from Latin America. Journal of Population Economics 10 (4): 377-86. http://dx.doi.org/10.1007/s001480050049

Psachalopoulos, G., and A.M. Arriagada. (1989). The Determinants of Early Age Human Capital Formation: Evidence from Brazil. Economic Development and Cultural Change, 37 (4): 683-704. http://dx.doi.org/10.1086/451755

Salahuddin, K. (1981). Aspects of Child Labour in Bangladesh" in 'Disadvantage Children in Bangladesh: Some Reflections' Women for Women. Dhaka, Bangladesh.

Schultz, T. (1963). The Economic Value of Education. New York: Columbia Univ. Press.

Skoufias, E. (1994). Market Wages, Family Composition and the Time Allocation of Children in Agricultural Households. Journal of Development Studies, 30 (2) January 1994: 335-360. http://dx.doi.org/10.1080/00220389408422318

Strauss, J., and D. Thomas. (1995). Human Resources: Empirical Modelling of Household and Family Decisions", in J. Berhman and T.N. Srinivasan (eds), Handbook of Development Economics, vol. IIIA, Amsterdam: Elsevier.

Tansel, A. (1993). School attainment, parental education and gender in Cote D'Ivoire and Ghana'. Center Discussion Paper No. 692, Yale University. New Haven, CT.

United Republic Of Tanzania, UTR. (1995). Education and Training Policy, Ministry of 
Education and Culture. Dar es Salaam.

\section{Notes}

Note 1. These other primary schools are Mgwasi, Gwanga, Njoro, Mgandu, Gonzanya, Kirangare, Mongoloma, Mwanya, Marien, Ndivem, Emuguri, Majevu, Jitengeni, Mbono, Dido, Minyala, Changarawe, Kidundai, Kitala, Makasa, Maganda, Njagu, and Msasa.

Note 2. Akabayashi and Psachropoulos. (1999). Al-Samarrai, and Tessa (1998), and Mason and Khandker (1996)

Note 3. Birdsall and Orivel. (1996). for Mali, Lavy (1996) for Ghana, and Grootaert (1999) for Cote dÍvoire.

Note 4. Orazem et al.(2004), Khanam and Russell (2005), Maitra (2003) and Orazem and Gunnarsson (2003)

Note 5. Mueller (1976) and Caldwell (1990).

Note 6 . The interaction of the environmental degradation situations and the logarithm of the total household income. The reason for its inclusion is given in the text.

\section{Copyright Disclaimer}

Copyright reserved by the author(s).

This article is an open-access article distributed under the terms and conditions of the Creative Commons Attribution license (http://creativecommons.org/licenses/by/3.0/). 